\title{
Activities of Aromatic L-Amino Acid Decarboxylase with L-Dopa as Substrate in Brush-Border- and Basolateral Membranes and Cytoplasm Obtained from Rat Renal Cortex
}

\author{
Nobuhiko YAMAZAKI and Jun-ichi SUDO \\ Department of Toxicology and Clinical Pharmacology. Faculty of Pharmaceutical Sciences, \\ Higashi-Nippon-Gakuen University. Ishikari-Tobetsu. Hokkaido 061 -02. Japan \\ Accepted November 21, 1987
}

\begin{abstract}
Activities of aromatic L-amino acid decarboxylase (AADC) with L-dopa as its substrate were determined in the plasma membranes and other cellular components isolated from rat renal cortex. The cytoplasm contained a high level of AADC activity, but much lower levels were found in the brush-border- and basolateral membranes. The main site involved in the formation of dopamine from $\mathrm{L}$ dopa was considered to be the cytoplasm, with participation of neither the brushborder- nor the basolateral membranes.
\end{abstract}

Aromatic L-amino acid decarboxylase (AADC; EC 4.1.1.28) is an enzyme which decarboxlates L-dopa and L-5-hydroxytryptophan into dopamine and serotonin, respectively (1), and it occurs in several organ tissues (2). In the kidney, it has been reported that this AADC localizes in the renal proximal and distal tubules (3), and that dopamine is formed from plasma $L$-dopa in the kidney and is excreted into the urine $(4,5)$. Three sites can be proposed as possible renal cellular site(s) where the decarboxylation of L-dopa to dopamine occurs, if the concerned nephron segment is considered to be restricted to the proximal tubules: brush-border membranes, basolateral membranes and other cellular components.

In order to investigate the proximal tubular site(s) involved in the decarboxylation of Ldopa to dopamine, we prepared brush-borderand basolateral membranes and subcellular components from the rat kidney cortex, and studied the AADC activities with a substrate of $L$-dopa in the prepared fractions.

Male Wistar rats weighing $200-250 \mathrm{~g}$ were used. Under ether-anesthesia, the kidneys were exposed through a ventral incision, and perfused via the abdominal aorta with $0.9 \%$ saline, and removed. The kidneys were sliced along the cortico-medullary axis, and the pieces of cortex were cut out and collected.
For rough subcellular fractionations, the pieces of renal cortex were homogenized $(1: 9, \mathrm{~W} / \mathrm{V})$ in solution $\mathrm{A}$, which consisted of $0.25 \mathrm{M}$ sucrose, $1 \mathrm{mM}$ ethylenediamine tetraacetic acid disodium (EDTA $\cdot \mathrm{Na}_{2}$ ), $0.1 \mathrm{mM} \alpha$ toluenesulfonyl fluoride (TSF), a protease inhibitor, and $10 \mathrm{mM}$ Tris- $\mathrm{HCl}(\mathrm{pH} 7.5)$, by a glass/Teflon Potter homogenizer. The homogenate was then centrifuged, in turn, at $1.000 \times \mathrm{g}$ for $10 \mathrm{~min}, 10,000 \times \mathrm{g}$ for $30 \mathrm{~min}$ and $100,000 \times \mathrm{g}$ for $60 \mathrm{~min}$. The sediments obtained were resuspended in solution $A$.

Brush-border - and basolateral membranes were isolated by methods employing calcium precipitation and Percoll density gradient centrifugation (6,7). Every solution used for the above isolation contained $0.1 \mathrm{mM}$ TSF to protect AADC against proteases.

For characterization of each fraction, the activities of the following enzymes were determined as reported previously (8): leucine aminopeptidase as a marker for brush-border membranes. $\mathrm{Na}^{+}-\mathrm{K}^{+}$-ATPase for basolateral membranes, cytochrome $c$-oxidase for mitochondria, $\beta$-D-glucuronidase for lysosomes, uricase for peroxisomes, glucose-6phosphatase for microsomes and lactate dehydrogenase for the cytoplasm. Protein amount was determined by the method of Kresze (9), a procedure which is an improvement of the method of Lowry et al. (10). 
AADC activity was determined by modifying the method of Nagatsu et al. (11). The preincubation medium consisted of $30 \mathrm{mM}$ $\mathrm{NaH}_{2} \mathrm{PO}_{4}-\mathrm{Na}_{2} \mathrm{HPO}_{4}$ buffer (pH 7.2), $0.3 \mathrm{mM}$ EDTA $\mathrm{Na}_{2}, 0.17 \mathrm{mM}$ ascorbic acid. $0.01 \mathrm{mM}$ pyridoxal phosphate, $0.1 \mathrm{mM}$ pargyline hydrochloride and $0.1 \mathrm{mM} \mathrm{TSF}$. The medium in volume of $485 \mu$ l was put into a reaction vial and then preincubated at $37^{\circ} \mathrm{C}$ for $2 \mathrm{~min}$. After adding $10 \mu \mathrm{l}$ of sample and $5 \mu$ of 40 $\mathrm{mM} L$-dopa to the medium, the mixture was then incubated at $37^{\circ} \mathrm{C}$ for $30 \mathrm{~min}$. The final concentration of L-dopa in this mixture was $0.4 \mathrm{mM}$ : this concentration was approximately 4 times the $K_{m}$ value $(0.0935 \pm 0.0240$ $\mathrm{mM}$, mean \pm S.D.) which was determined using the homogenate from the rat renal cortex as the enzyme source. After the incubation, $400 \mu l$ of $0.2 \mathrm{~N}$ perchloric acid and $20 \mu \mathrm{l}$ of $2 \mu \mathrm{g} / \mathrm{ml}$ dihydroxy-benzylamine hydrobromide were added, which, respectively. stopped the enzymatic reaction and served as the internal standard for the HPLC method described below. Treatment of this aliquot and the HPLC determination was done according to the method of Riggin and Kissinger (12). HPLC conditions employed in this study were as follows: isocratic elution: mobile phase, aqueous solution consisting of $30 \mathrm{mg} / 1$ sodium octyl sulfate, $2 \mathrm{mM}$ EDTA $\cdot \mathrm{Na}_{2}, 0.1 \mathrm{M}$ chloroacetic acid $(\mathrm{pH}$ 3.0, adjusted by crystalline sodium hydroxide): flow rate, $1 \mathrm{ml} /$ min; detection, voltammetry (L-ECD-6A ECD voltammetry detector; Shimadzu Co. Kyoto. Japan; detector potential was set at $0.8 \mathrm{~V}$ versus the $\mathrm{Ag} / \mathrm{AgCl}$ electrode); column. Shim-pack CLC-ODS $(6 \mathrm{~mm} \times 150 \mathrm{~mm}, 5 \mu \mathrm{m}$; Shimadzu Co.); column temperature, $30^{\circ} \mathrm{C}$.

Table 1 shows the specific activities of the main marker enzymes and AADC in the homogenate and the roughly-separated subcellular fractions. The supernatant fraction obtained by centrifugation at $100,000 \times \mathrm{g}$ for $60 \mathrm{~min}$ contained the highest activity of lactate dehydrogenase and relatively lower activities of the other marker enzymes as compared to the other fractions. In this fraction, the highest AADC activity was also observed as com-

Table 1. Specific activities of marker enzymes and AADC in the homogenate and the subcellular fractions obtained from the rat renal cortex

\begin{tabular}{lccccc}
\hline Enzyme & Homogenate & Sediment 1 & Sediment 2 & Sediment 3 & Supernatant \\
\hline Leucine & $54.8 \pm 3.6$ & $57.6 \pm 4.6$ & $181.0 \pm 10.9$ & $229.8 \pm 30.4$ & $16.2 \pm 2.5$ \\
aminopeptidase & $(1.00)$ & $(1.05)$ & $(3.30)$ & $(4.19)$ & $(0.30)$ \\
Na+-K+-ATPase & $43.8 \pm 10.8$ & $80.4 \pm 24.3$ & $142.6 \pm 26.1$ & $147.7 \pm 45.7$ & $0.1 \pm 5.2$ \\
& $(1.00)$ & $(1.84)$ & $(3.26)$ & $(3.37)$ & $(0.002)$ \\
Uricase & $46.4 \pm 9.8$ & $70.8 \pm 20.6$ & $139.3 \pm 34.8$ & $104.3 \pm 19.6$ & $32.7 \pm 10.8$ \\
& $(1.00)$ & $(1.53)$ & $(3.00)$ & $(2.25)$ & $(0.70)$ \\
Glucose-6- & $79.2 \pm 8.5$ & $109.5 \pm 22.2$ & $171.8 \pm 19.1$ & $277.2 \pm 55.4$ & $45.7 \pm 11.5$ \\
phosphatase & $(1.00)$ & $(1.38)$ & $(2.17)$ & $(3.50)$ & $(0.58)$ \\
Lactate & $646 \pm 6$ & $254 \pm 32$ & $181 \pm 34$ & $159 \pm 28$ & $2385 \pm 416$ \\
dehydrogenase & $(1.00)$ & $(0.39)$ & $(0.28)$ & $(0.25)$ & $(3.69)$ \\
B-D-Glucuronidase & $1.01 \pm 0.15$ & $1.49 \pm 0.20$ & $2.10 \pm 0.19$ & $0.64 \pm 0.08$ & $0.78 \pm 0.20$ \\
& $(1.00)$ & $(1.48)$ & $(2.08)$ & $(0.63)$ & $(0.77)$ \\
Cytochrome c-oxidase & $818 \pm 166$ & $901 \pm 77$ & $1655 \pm 181$ & $232 \pm 44$ & $3.7 \pm 19.4$ \\
& $(1.00)$ & $(1.10)$ & $(2.02)$ & $(0.28)$ & $(0.005)$ \\
\hline AADC & $6.02 \pm 1.07$ & $2.68 \pm 0.17$ & $4.00 \pm 1.59$ & $4.08 \pm 0.71$ & $29.68 \pm 3.96$ \\
& $(1.00)$ & $(0.45)$ & $(0.66)$ & $(0.68)$ & $(4.93)$ \\
\hline
\end{tabular}

Abbreviations: AADC, aromatic L-amino acid decarboxylase: Sediment 1, sediment obtained by centrifugation at $1.000 \times \mathrm{g}$ for $10 \mathrm{~min}$; Sediment 2 , sediment obtained by centrifugation at $10,000 \times \mathrm{g}$ for 30 min: Sediment 3 , sediment obtained by centrifugation at $100,000 \times \mathrm{g}$ for $60 \mathrm{~min}$; Supernatant, supernatant obtained by centrifugation at $100,000 \times \mathrm{g}$ for $60 \mathrm{~min}$. The number of experiments was 6 , and values are given as means \pm S.D. The enzyme activity is given as $\mathrm{U} / \mathrm{g} \cdot$ protein. In the measurments of $\mathrm{Na}^{+}-\mathrm{K}^{+}$ATPase and glucose-phosphatase, one unit means 1 mole of Pi hydrolyzed from the substrate per min. Relative activities, which are shown in parentheses, were calculated by dividing the mean value in each fraction by the mean value in the homogenate. 
pared with the other fractions. The AADC activities in fractions other than the supernatant were found to be as low as that in the homogenate. Table 2 shows a comparison of the specific activities of the marker enzymes and $A A D C$ in the homogenate, brush-border membranes and basolateral membranes. There was a clear-cut rise in the activity of leucine aminopeptidase by a factor of 13.77 in the brush-border membranes and also a clear-cut rise in the activity of $\mathrm{Na}^{+}-\mathrm{K}^{+}$ATPase by a factor of 8.85 in the basolateral membranes. In contrast, the other marker enzymes showed relatively lower activities in the two membranes. The activities of lactate dehydrogenase, a cytoplasmic marker, were extremely low in the two membranes. This indicated that the two membrane fractions were effectively separated from the other cellular components, especially from the cytoplasm. The activities of AADC were very markedly lower in the two membranes as compared with that in the supernatant fraction.

In this study, using the fractions obtained from the renal cortex, intracellular localization of AADC was investigated. Although the renal cortex is composed of the glomeruli. proximal tubules and other distally located tubules (cortical distal tubules and collecting tubules). most of the tubular segments are generally known to be proximal tubules. Accordingly, our results might almost reflect the enzymatic activities distributed in the proximal tubules.

When the site of the dopamine synthesis was considered to be mainly on the proximal tubules, the basolateral and brush-border membranes were the first "gates" in relation to the access process of L-dopa as a substrate for AADC. Our study denoted that the AADC activities with L-dopa as its substrate were distributed most highly in the cytoplasm, and lower amounts were found in the basolateral and brush-border membranes obtained from the rat renal cortex. Although the Iow AADC activities in the two membranes were considered to be due to contamination by the cytoplasm, the possibility that AADC may locate in the membranes could not be excluded. However, even this enzyme does exist in these membranes, the intraluminal formation of dopamine from L-dopa filtered through the glomeruli was speculated to be relatively lower in comparison to that of the cytoplasm.

Above all, it should be noted that the AADC activity was the highest in the cytoplasm. From this finding, it is speculated that dopamine is formed from L-dopa by AADC in the

Table 2. Specific activities of marker enzymes and AADC in the homogenate, brush-border membranes and basolateral membranes obtained from the rat renal cortex

\begin{tabular}{lccc}
\hline Enzyme & Homogenate & $\begin{array}{c}\text { Brush-border } \\
\text { membranes }\end{array}$ & $\begin{array}{c}\text { Basolateral } \\
\text { membranes }\end{array}$ \\
Leucine & $12.3 \pm 6.0$ & $-582.6 \pm 49.8$ & $98.1 \pm 11.1$ \\
aminopeptidase & $(1.00)$ & $(13.77)$ & $(2.32)$ \\
Na+-K+-ATPase & $48.0 \pm 8.1$ & $0.9 \pm 17.3$ & $425.0 \pm 17.6$ \\
Uricase & $(1.00)$ & $(0.02)$ & $(8.85)$ \\
& $43.8 \pm 5.2$ & $33.0 \pm 7.0$ & $77.4 \pm 19.7$ \\
Glucose-6- & $(1.00)$ & $(0.75)$ & $(1.77)$ \\
phosphatase & $67.7 \pm 19.0$ & $48.4 \pm 11.2$ & $376.4 \pm 109.6$ \\
Lactate & $(1.00)$ & $(0.71)$ & $(5.56)$ \\
dehydrogenase & $635.7 \pm 169.0$ & $33.6 \pm 10.8$ & $116.7 \pm 11.3$ \\
$\beta$-D-Glucuronidase & $(1.00)$ & $(0.05)$ & $(0.18)$ \\
& $1.41 \pm 0.15$ & $0.16 \pm 0.02$ & $0.38 \pm 0.10$ \\
Cytochrome $C$-oxidase & $(1.00)$ & $(0.11)$ & $(0.27)$ \\
& $715.5 \pm 86.6$ & $78.6 \pm 38.3$ & $85.8 \pm 41.5$ \\
AADC & $(1.00)$ & $(0.11)$ & $(0.12)$ \\
\hline
\end{tabular}

Explanations are as in Table 1. 
cytoplasm in the proximal tubular cells, that the intracellularly formed dopamine is released to the peritubular and/or intraluminal fluids, and that dopamine released locally in the kindney plays multiple physiological roles $(13-16)$. As to the urinary excreted dopamine, there have been no reports that dopamine has any physiological functions at the luminal site. Therefore, dopamine that was formed intraluminally and/or released into the lumen might be excreted into the urinary fluid without exerting any physiological functions, whereas the intraluminally reabsorbed dopamine may have a possible role in some functions. The dopamine which was finally released to the peritubular fluid might play the most important role in the physiological functions of the kidney.

\section{References}

1 Lovenberg, W., Weissbach, H. and Udenfriend, S.: Aromatic L-amino acid decarboxylase. J. Biol. Chem. 237, 89-93 (1962)

2 Rahman, M.K., Nagatsu, T. and Kato, T.: Aromatic L-amino acid decarboxylase activity in central and peripheral tissues and serum of rats with L-dopa and L-hydroxytryptophan as substrates. Biochem. Pharmacol. 30, 645-649 (1981)

3 Goldstein, M., Fuxe, K. and Hokfelt, T: Characterization and tissue localization of catecholamine synthesizing enzymes. Pharmacol. Rev. 24, 293309 (1972)

4 Lee, M.R.: Dopamine and the kidney. Clin. Sci. $62,439-448$ (1982)

5 Baines, A.D. and Chan, W.: Production of urine free dopamine from Dopa: A micropuncture study. Life Sci. 26, 253-259 (1980)

6 Inui, K., Okano, T., Takano, M., Kitazawa, S. and Hori, R.: A simple method for the isolation of basolateral plasma membrane vesicles from rat kidney cortex. Enzyme activities and some properties of glucose transport. Biochim. Biophys. Acta 647, 150-154 (1981)
7 Takano, M., Inui, K., Okano, T., Saito, H. and Hori, R.: Carrier-mediated transport systems of tetraethylammonium in rat renal brush-border and basolateral membrane vesicles. Biochim. Biophys. Acta 773, 113-124 (1984)

8 Sudo, J. and Tanabe, T.: Distributions of postproline cleaving enzyme-, converting enzyme-. trypsin- and chymotrypsin-like activites in various nephron segments and in brush-border membranes isolated from rat kidney. Chem. Pharm. Bull. (Tokyo) 33, 1694-1702 (1985)

9 Kresze, G.-B.: Methods for protein determination. in Methods of Enzymatic Analysis. Third ed., Edited by Bergmeyer, H.U., Vol. 2, p. 88-92. Verlag Chemie $\mathrm{GmbH}$, Weinheim, Deerfield Beach and Basel (1983)

10 Lowry, O.H., Rosebrough, N.J., Farr, A.L. and Randall, R.J.: Protein measurement with the Folin phenol reagent. J. Biol. Chem. 193, 265275 (1951)

11 Nagatsu, T., Yamamoto, T, and Kato, T.: A new and highly sensitive voltammetric assay for aromatic L-amino acid decarboxylase activity by high-performance liquid chromatography. Anal. Biochem. 100, 160-165 (1979)

12 Riggin, R.M. and Kissinger, P.T.: Determination of catecholamines in urine by reverse-phase liquid chromatography with electrochemical detection. Anal. Chem. 49, 2109-2111 (1977)

13 Goldberg, L.I.: Cardiovascular and renal actions of dopamine: Pontential clinical applications. Pharmacol. Rev. 24, 1-29 (1972)

14 Imbs, J.-L., Schmidt, M. and Schwartz, J.: Effect of dopamine on renin secretion in the anesthetized dog. Eur. J. Pharmacol. 33, 151157 (1975)

15 McGiff, J.C. and Burns, C.R.: Separation of dopamine natriuresis from vasodilation: Evidence for dopamine receptors. J. Lab. Clin. Med. 70, 892 (1967)

16 Cuche, J.-L., Marchand, G.R., Creger, R.F., Lang, F.C. and Knox, F.G.: Phosphaturic effect of dopamine in dogs. Possible role of intrarenally produced dopamine in phosphate regulation. J. Clin. Invest. 58, 71-76 (1976) 